\title{
Pilot Balloon Valve Device
}

National Cancer Institute

\section{Source}

National Cancer Institute. Pillot Balloon Valve Device. NCI Thesaurus. Code C50261.

A two-way valve designed to control the pressure in an endotracheal tube cuff as

introduced through a pilot balloon. 